Prepared for the U.S. Department of Energy

under Contract DE-AC05-76RL01830

\title{
LED Surgical Task Lighting Scoping Study: A Hospital Energy Alliance Project
}

JR Tuenge

January 2011

\section{Pacific Northwest} NATIONAL LABORATORY

Proudly Operated by Battelle Since 1965 



\title{
DISCLAIMER
}

This report was prepared as an account of work sponsored by an agency of the United States Government. Neither the United States Government nor any agency thereof, nor Battelle Memorial Institute, nor any of their employees, makes any warranty, express or implied, or assumes any legal liability or responsibility for the accuracy, completeness, or usefulness of any information, apparatus, product, or process disclosed, or represents that its use would not infringe privately owned rights. Reference herein to any specific commercial product, process, or service by trade name, trademark, manufacturer, or otherwise does not necessarily constitute or imply its endorsement, recommendation, or favoring by the United States Government or any agency thereof, or Battelle Memorial Institute. The views and opinions of authors expressed herein do not necessarily state or reflect those of the United States Government or any agency thereof.

\author{
PACIFIC NORTHWEST NATIONAL LABORATORY \\ operated by \\ BATTELLE \\ for the \\ UNITED STATES DEPARTMENT OF ENERGY \\ under Contract DE-AC05-76RL01830
}

Printed in the United States of America
Available to DOE and DOE contractors from the Office of Scientific and Technical Information,
P.O. Box 62, Oak Ridge, TN 37831-0062;
ph: (865) 576-8401
fax: (865) 576-5728
email: reports@adonis.osti.gov

\author{
Available to the public from the National Technical Information Service, \\ U.S. Department of Commerce, 5285 Port Royal Rd., Springfield, VA 22161 \\ ph: (800) 553-6847 \\ fax: (703) 605-6900 \\ email: orders@ntis.fedworld.gov \\ online ordering: http://www.ntis.gov/ordering.htm
}

This document was printed on recycled paper. 



\section{LED Surgical Task Lighting Scoping Study: A Hospital Energy Alliance Project}

JR Tuenge

January 2011

Prepared for

the U.S. Department of Energy

under Contract DE-AC05-76RL01830

Pacific Northwest National Laboratory

Richland, Washington 99352 



\section{Acronyms and Abbreviations}

ASHE

CALiPER

CCT

CBECS

DOE

FDA

Halogen

HCAHPS

HEA

HID

IEC

IR

IESNA

LED

$\operatorname{lm}$

lx

$\mathrm{m}^{2}$

ORs

PNNL

UV

W
American Society for Healthcare Engineering

Commercially Available LED Product Evaluation and Reporting program

correlated color temperature

Commercial Buildings Energy Consumption Survey

Department of Energy

Food and Drug Administration

tungsten-halogen

Hospital Consumer Assessment of Healthcare Providers and Systems

Hospital Energy Alliance

high intensity discharge

International Electrotechnical Commission

infrared

Illuminating Engineering Society of North America

light-emitting diode

lumen(s)

$\operatorname{lux}$

square meter(s)

operating rooms

Pacific Northwest National Laboratory

ultraviolet

watt(s) 



\section{Contents}

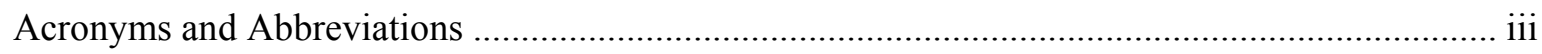

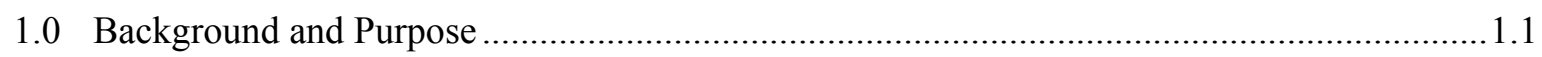

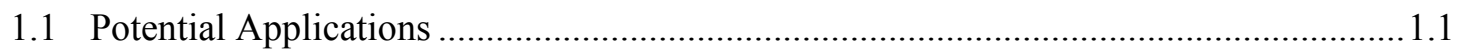

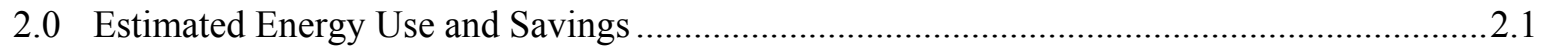

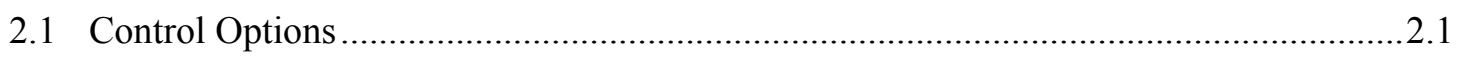

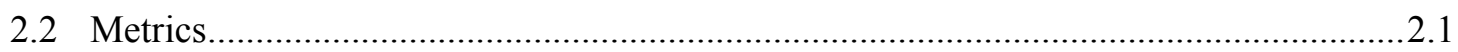

3.0 Preliminary Survey of Surgical Lamp Performance …...................................................... 3.1

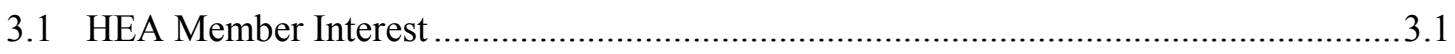

3.2 Potential Inhibitors to Increased Use of LED Surgical Lighting .................................... 3.1

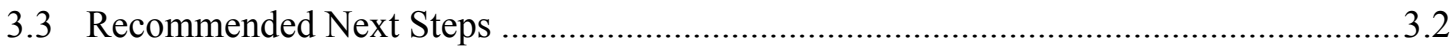

$4.0 \quad$ Post-Project Analysis.............................................................................................. 4.1

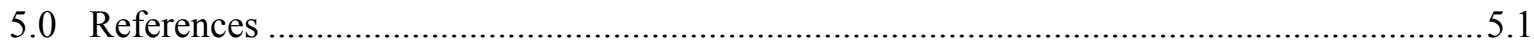

Appendix A Preliminary Survey of Surgical Lamp (Task Light) Performance ...........................A.1 



\subsection{Background and Purpose}

In October 2010, the Hospital Energy Alliance (HEA) Lighting Project Team selected light-emitting diode (LED) surgical task lighting as a project to pursue during FY 11. Tungsten-halogen (halogen) lamps have traditionally been used to light surgical tasks in hospitals, even though they are in many respects ill-suited to the application due to the large percentage of radiant energy outside the visible spectrum and issues with color rendering/quality. LED technology offers potential for adjustable color and improved color rendition/quality, while reducing side effects from non-visible radiant energy. LED could also offer significant energy savings, although this is a fairly narrow application in the larger commercial building energy use sector.

The purpose of this scoping study is to:

- define the potential applications for this product category

- establish metrics and criteria to characterize key performance parameters

- complete a preliminary survey of surgical lamp (task light) performance

- determine associated energy savings and cost-effectiveness

- determine current halogen kilowatt-hour footprint, and potential national impact

- determine if HEA members are interested in pursuing additional project activities such as informational webinars, specification development, and demonstration projects

- recommend next steps to the U.S. Department of Energy (DOE) and HEA membership.

\subsection{Potential Applications}

The products covered in this scoping study are defined in 21 CFR 878.4580 as "surgical lamps," and more specifically as "major surgical luminaires" in International Electrotechnical Commission (IEC) standard 60601-2-41. Potential applications include hospital surgical suites, both new and existing. The articulated luminaires used in these applications are suspended from the ceiling or from floor-mounted booms and feature near-field converging-diverging beams that are uncommon in architectural applications. Minor surgery and exam/diagnostic lights are excluded from this study, as are any luminaires recessed into the ceiling. 



\subsection{Estimated Energy Use and Savings}

According to a representative from the American Hospital Association, there are approximately 49,141 operating rooms (ORs) in the U.S. (Woodin 2010). John D'Angelo of the Cleveland Clinic estimates there are 100 surgical lamps distributed among 30 of the ORs in his hospital network, operated roughly 2,150 hr/yr (D’Angelo 2010). Assuming these figures and ratios are typical, there are approximately 163,803 surgical lamps in the U.S. A preliminary survey of the Food and Drug Administration (FDA)-listed major surgical luminaires shows available products average approximately $168 \mathrm{~W}$ rated input power per halogen luminaire, excluding transformer losses (FDA 2011; see Appendix A for details). Assuming exclusive use of major (zero minor) surgical luminaires with halogen (zero high intensity discharge [HID] or LED) lamps in operating rooms, these products consume as much as 27.6 MW nationwide and 0.06 TWh annually. HEA members comprise approximately $27 \%$ of the industry based on square footage (Sandahl 2010); overall impact will further depend on the percentage of adopting members and current level of penetration.

Given that beams converge and then diverge near-field, LM-79 far-field goniophotometry testing is not applicable. The large housing sizes (nearly 24 inch diameter on average) and tightly controlled beams also preclude the use of integrating spheres. For these reasons, and given the available data and relevant criteria, it appears efficacy is best characterized in terms of lux per watt (rather than lumens per watt) for these products. The Pacific Northwest National Laboratory (PNNL) reviewed the major surgical luminaires and found that the average rated initial efficacy is $1848 \mathrm{~lx} / \mathrm{W}$ for LED, versus $699 \mathrm{~lx} / \mathrm{W}$ for halogen. These values should be scaled by $70 \%$ and $95 \%$ for LED and halogen, respectively, for applesto-apples comparison of maintained efficacy. This yields an estimated $49 \%$ average reduction in connected load by switching to LED.

\subsection{Control Options}

Halogen is dimmable, so LED dimmability probably won't offer additional energy savings. However, it is important to note that whereas halogen will inevitably shift to lower/warmer correlated color temperatures (CCTs) as it is dimmed, LED won't necessarily exhibit any such change in color-this may increase functionality (and operating hours) at reduced wattage.

\subsection{Metrics}

Metrics and criteria that might be used to characterize key performance parameters in a product specification include:

- minimum luminous efficacy $(\mathrm{lx} / \mathrm{W})$

- minimum light output (lx)

- dimming range (without color shift or flicker)

- spatial distribution (light field diameter and depth of illumination)

- shadow dilution/mitigation

- chromaticity and tolerances (CCT, distance from the Planckian locus, etc.) 
- chromaticity adjustment range

- color rendition/quality (color rendering index, R9, color quality scale, etc.)

- uniformity of illuminance and color within the beam

- lumen and color maintenance

- radiation outside the visible spectrum

- minimum power factor and maximum total harmonic distortion (at full output and dimmed)

- electromagnetic interference restrictions

- flicker and noise restrictions

- maximum luminaire surface temperature

- luminaire cleanability. 


\subsection{Preliminary Survey of Surgical Lamp Performance}

Key findings from the preliminary survey include:

- Most performance claims are framed in IEC language, but surgical lighting manufacturers are generally reluctant (and apparently not expected) to share laboratory reports containing measurements to support these claims.

- The CALiPER program (EERE 2010a) has revealed inaccurate performance claims for initial output from commercial and consumer products, while also demonstrating that a number of these LED products fall well short of their rated useful lifetimes.

\subsection{HEA Member Interest}

PNNL has worked closely with the HEA Project Chairperson, John D'Angelo of the Cleveland Clinic, and held calls to discuss this project with the HEA Lighting Project Team. Member feedback to date includes the following:

- Cleveland Clinic - Very interested in this project and is chairing the HEA Surgical Lighting Project Team. Has already installed a number of LED surgical lamps, but has no formal specification. Will soon retrofit two ORs, which could serve as demonstration sites for a new HEA specification. Emphasizes the importance of interviewing and observing surgical staff to determine actual needs and activity. Also emphasizes the need to understand and communicate the potential improvements to quantity and quality of illumination, with simultaneous reductions in non-visible radiation potentially resulting in improved Hospital Consumer Assessment of Healthcare Providers and Systems (HCAHPS) surveys and speed of recovery. Product cost is a hurdle but may be mitigated through standardization and bulk purchasing.

- Sinai Health System - Very interested. Haven't used LED surgical lamps yet. Will soon have several new ORs, which might serve as demonstration sites for a new HEA specification.

- Healthcare REIT - Very interested.

- IASIS Healthcare - Not interested. Big investment for low returns, and surgical staff resist change.

- HealthSouth - Doesn't have any operating rooms, only interested in patient exam room lights.

- Inova Health System - Very interested.

- American Society for Healthcare Engineering (ASHE) - Very interested in making its larger membership aware of the therapeutic and energy savings benefits of LED surgical lighting. ASHE has offered to host a webinar to its membership in an effort to increase awareness and gain support for an ongoing HEA project focused on LED surgical lighting.

\subsection{Potential Inhibitors to Increased Use of LED Surgical Lighting}

Potential roadblocks to increased use of LED for surgical lighting include the following.

- Hospital resources

- Hospitals may not have personnel qualified to review product submittals. 
- A qualified product list (populated and maintained by others) may be desirable.

- Manufacturer resistance

- Manufacturers of products intended for these applications may resist compliance with an HEA specification because these companies may not be familiar with photometric or colorimetric criteria, and may not be accustomed to the burden of photometric testing or publishing photometric performance data.

- Product cost

- A handful of products are available, but while some of those tested by HEA members have performed well, they can be significantly more expensive. The Cleveland Clinic found that an LED lighthead can cost more than twice that of an equivalent halogen product (D'Angelo 2011).

- In addition, test procedures can add cost to an already expensive product, and utilities may not offer incentives or rebates for this limited-scope application. More data will be needed to ascertain cost-effectiveness across a number of regions and HEA members.

\subsection{Recommended Next Steps}

Based on the findings of this study, the HEA Surgical Lighting Project Team recommends the following steps.

- Identify two or more demonstration sites (Feb 2011).

- Host a webinar for HEA membership, outlining results of the scoping study and featuring a discussion by Cleveland Clinic on its experience with LED surgical lighting products. Follow this with a similar webinar hosted by ASHE to reach the broader hospital community. As part of both webinars, ask attendees to provide feedback on the types and amounts of surgical lighting equipment in their facilities, familiarity with LED surgical lighting, and interest in getting involved in this project (March 2011).

- Develop a field-measurement procedure to allow HEA members to verify initial performance and to track maintenance of light output and color of LED surgical task lights. This procedure should be primarily based on the IEC standard to facilitate evaluation of readily available product information, with additions as needed to align with Illuminating Engineering Society of North America (IESNA) recommendations and HEA member criteria (April 2011).

- Develop guidelines for auditing existing systems and monitoring LED energy use (May 2011).

- Develop a draft LED product specification (May 2011).

- Coordinate with utilities, including information for HEA members related to utility rebates and incentives.

- Produce reports from case studies and demonstration projects detailing reduced lighting power, photometric performance, and surgical staff satisfaction (Sept 2011).

- Produce reports from possible field investigations (TBD).

- Investigate possible Volume Purchase Program (FY 12). 


\subsection{Post-Project Analysis}

The following additional analysis will be performed upon project completion.

- Depth of deployment will be measured based on interviews with partners to determine:

- kilowatt-hours of energy saved

- percent reduction in energy use for installed base

- percent of installed base converted to LED

- owner satisfaction with quality and quantity of light

$\circ$ initial

- maintained

- Measurement and verification to determine actual versus installed savings will be primarily via power monitoring associated with case studies and demonstration projects.

- The data collected for measurement and verification, along with current electricity prices, will be used to compare the conserved cost of energy calculations resulting from the engineering estimates with that calculated based on measured data to determine cost-curve effectiveness. 



\subsection{References}

21 CFR 878.4580. “Surgical lamp.” Code of Federal Regulations, U.S. Food and Drug Administration.

ANSI/IESNA RP-29-06. "Lighting for Hospitals and Health Care Facilities." American National Standards Institute, Washington, DC.

D’Angelo, J. 2010. Hospital Energy Alliance (HEA) Lighting Project Team conference call with John D'Angelo (Cleveland Clinic). November 1, 2010.

D’Angelo, J. 2011. Email to Jason Tuenge (PNNL) from John D'Angelo (Cleveland Clinic), "RE: Preliminary Survey of Surgical Lamp (Task Light) Performance,” January 13, 2011.

EERE - U.S. Department of Energy, Office of Energy Efficiency and Renewable Energy. 2009. Lifetime of White LEDs. PNNL-SA-50969. June 2009. Developed by Pacific Northwest National Laboratory for the EERE Building Technologies Program, U.S. Department of Energy, Washington, DC.

EERE - U.S. Department of Energy, Office of Energy Efficiency and Renewable Energy. 2010a. CALiPER Program. Accessed on October 25, 2010, at http://www1.eere.energy.gov/buildings/ssl/caliper.html (last updated December 23, 2010).

EERE - U.S. Department of Energy, Office of Energy Efficiency and Renewable Energy. 2010b. Solid State Lighting Research and Development: Multi-Year Program Plan. March 2010. Washington, DC. Accessed April 1, 2010 at http://apps1.eere.energy.gov/buildings/publications/pdfs/ssl/ssl_mypp2010 web.pdf (undated webpage).

EERE - U.S. Department of Energy, Office of Energy Efficiency and Renewable Energy. Three-Part TINSSL Webinar Series: Understanding and Evaluating LM-79 \& LM-80 Reports for SSL Technology. Accessed on September 21, 2010 at http://www1.eere.energy.gov/buildings/ssl/test-reports webinar.html (last updated September 8, 2010).

FDA - U.S. Food and Drug Administration. 1998. Guidance Document for Surgical Lamp 510(k)s Guidance for Industry, FDA Reviewers/Staff and Compliance. July 13, 1998. U.S. Department Of Health and Human Services, Food and Drug Administration, Center for Devices and Radiological Health, General Surgical Devices Branch, Division of General and Restorative Devices, Office of Device Evaluation, Washington, DC.

FDA - U.S. Food and Drug Administration. 2011. Establishment Registration \& Device Listing. Accessed December 9, 2010 at http://www.accessdata.fda.gov/scripts/cdrh/cfdocs/cfRL/rl.cfm, product code FSY (last updated January 6, 2011).

IEC 60601-2-41. "Medical Electrical Equipment," Part 2-41: Particular Requirements for the Safety of Surgical Luminaires and Luminaires for Diagnosis. International Electrotechnical Commission, Geneva, Switzerland.

IESNA - Illuminating Engineering Society of North America. 2000. The IESNA Lighting Handbook, $9^{\text {th }}$ edition. June 2000. Illuminating Engineering Society of North America. New York, NY. 
IESNA/NALMCO RP-36-03. "Recommended Practice for Planned Indoor Lighting Maintenance." Illuminating Engineering Society of North America, New York, NY.

IES LM-79-08. "Electrical and Photometric Measurements of Solid-State Lighting Products." Illuminating Engineering Society, New York, NY.

Sandahl, L. 2010. Commercial Building Energy Alliances: Deploying Emerging Technologies. November 8, 2010. Innovation in ET Programs Emerging Technologies Summit, Sacramento, CA.

Woodin, D. 2010. Email to Jason Tuenge (PNNL) from Dale Woodin (American Hospital Association), "RE: ASHE Information on Surgical Room Lighting," January 7, 2010. 


\section{Appendix A}

\section{Preliminary Survey of Surgical Lamp (Task Light) Performance}





\section{APPENDIX A \\ Preliminary Survey of Surgical Lamp (Task Light) Performance}

Pacific Northwest National Laboratory (PNNL) conducted this study in support of the Hospital Energy Alliance Light-Emitting Diode (LED) Surgical Lighting Project, with the primary objective of better understanding the performance of LED surgical lighting compared to the tungsten-halogen (halogen) products typically used in operating rooms today.

Our analysis indicates input power for halogen surgical lamps averages approximately $168 \mathrm{~W}$, and equivalent LED products presently offer direct energy savings of roughly $82 \mathrm{~W}$ per light head. Both figures may be increased by $16 \%$ to include estimated transformer and power supply losses.

As John D'Angelo of Cleveland Clinic noted during a project team conference call on November 1, 2010, criteria and a test procedure are given in section 4.11.1 of the American National Standards Institute/Illuminating Engineering Society of North America (ANSI/IESNA) standard RP-29-06. However, a preliminary survey of available data suggests the industry is either unaware of or simply rejects the IESNA criteria, instead utilizing International Electrotechnical Commission (IEC) standard 60601-2-41. Additionally, unlike architectural luminaires covered by the various "LM" series test procedures offered by IESNA, the beams of light emitted by surgical task lights converge and then diverge near-field (at a distance of less than 5 times the diameter of the light head), as illustrated in Figure A.1. The IESNA-recommended test procedure for LED luminaires, LM-79, relies on far-field photometry and therefore cannot be used directly to characterize the performance of these products. However, aspects of LM-79 may merit consideration.
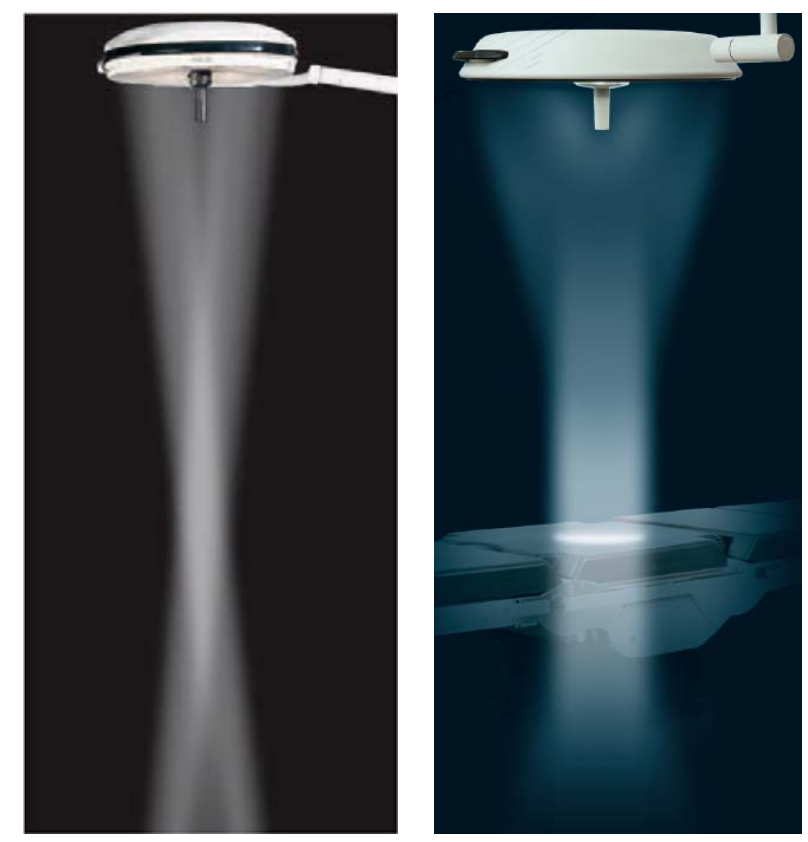

Figure A.1. Typical illustrations of converging-diverging beams 
Most performance claims are framed in IEC language, but manufacturers are generally reluctant (and apparently not expected) to share laboratory reports containing measurements to support these claims. Examination of pertinent performance parameters is essential when establishing equivalence. Parameters typically reported on cutsheets include:

- Central illuminance

- $\quad \mathrm{E}_{\mathrm{c}}$ is typically measured 1.0 meter below luminaire, along axis of rotational symmetry.

- This value must be between 40,000 and 160,000 lux per IEC.

- Light field diameter

- This is by default $\mathrm{d}_{10}$, the distance from point of $\mathrm{E}_{\mathrm{c}}$ outward to $10 \%$ of $\mathrm{E}_{\mathrm{c}}$.

- Sometimes $\mathrm{d}_{50}$ is also reported (this distance is shorter than $\mathrm{d}_{10}$ ).

- $\mathrm{d}_{50}$ must be at least $50 \%$ of $\mathrm{d}_{10}$ per IEC.

- Depth of illumination

- The sum of the distances upward and downward from the point of $\mathrm{E}_{\mathrm{c}}$ to the points at $60 \%$ of $\mathrm{E}_{\mathrm{c}}$.

- NOTE: Due to a change from $20 \%$ to $60 \%$ in the second edition of the IEC standard, released in 2009 , this parameter must be used carefully when comparing products. It is rarely clear whether reported values are per the first or the second edition, and first edition data was found to still be in circulation for currently available products. This likely creates a situation where products may be inadvertently compared apples-to-oranges.

- Shadow dilution

- IEC provides a procedure for quantifying percent reduction in $\mathrm{E}_{\mathrm{c}}$ for a set of scenarios.

- This set of parameters is rarely reported in manufacturer literature.

- Correlated color temperature

- Must be at least $3000 \mathrm{~K}$ and no more than $6700 \mathrm{~K}$ per IEC.

- Color rendering index

- Must be at least 85 per IEC.

- Non-visible radiation

- Total visible and non-visible irradiance, $\mathrm{E}_{\mathrm{e}}$, must be less than $1000 \mathrm{~W} / \mathrm{m}^{2}$ per IEC.

- Ratio of $E_{\mathrm{e}}$ to $\mathrm{E}_{\mathrm{c}}$ cannot exceed $6 \mathrm{~mW} / \mathrm{m}^{2} \mathrm{~lx}$ per IEC.

- NOTE: UV radiation below $400 \mathrm{~nm}$, though specifically restricted to $10 \mathrm{~W} / \mathrm{m}^{2}$ by the IEC, is typically not reported in manufacturer cutsheets.

- Operating life of the light source

- The survey found no mention of $\mathrm{L}_{70}$ or LM-80 for LED, much less in situ temperature measurement test (ISTMT). 
- Input wattage

- Often for light source(s) only, excluding transformer/ballast/driver losses.

- Sometimes not reported at all; this omission is most prevalent for LED.

Diameter of housing or reflector is also typically reported. An independent laboratory recently quoted PNNL \$6,750 per test. Given the expense and difficulty of testing these unwieldy products, it appears the best we can do at present is to simply require that products be listed by the Food and Drug Administration (FDA 1998) under product category FSY, ${ }^{1}$ hence ensuring that performance claims have at least been independently verified. ${ }^{2}$

Figure A.2 summarizes rated wattage and performance claims for illuminance and size of illuminated field, demonstrating that LED products appear quite competitive with halogen, at least in terms of performance (cost-effectiveness is another matter).

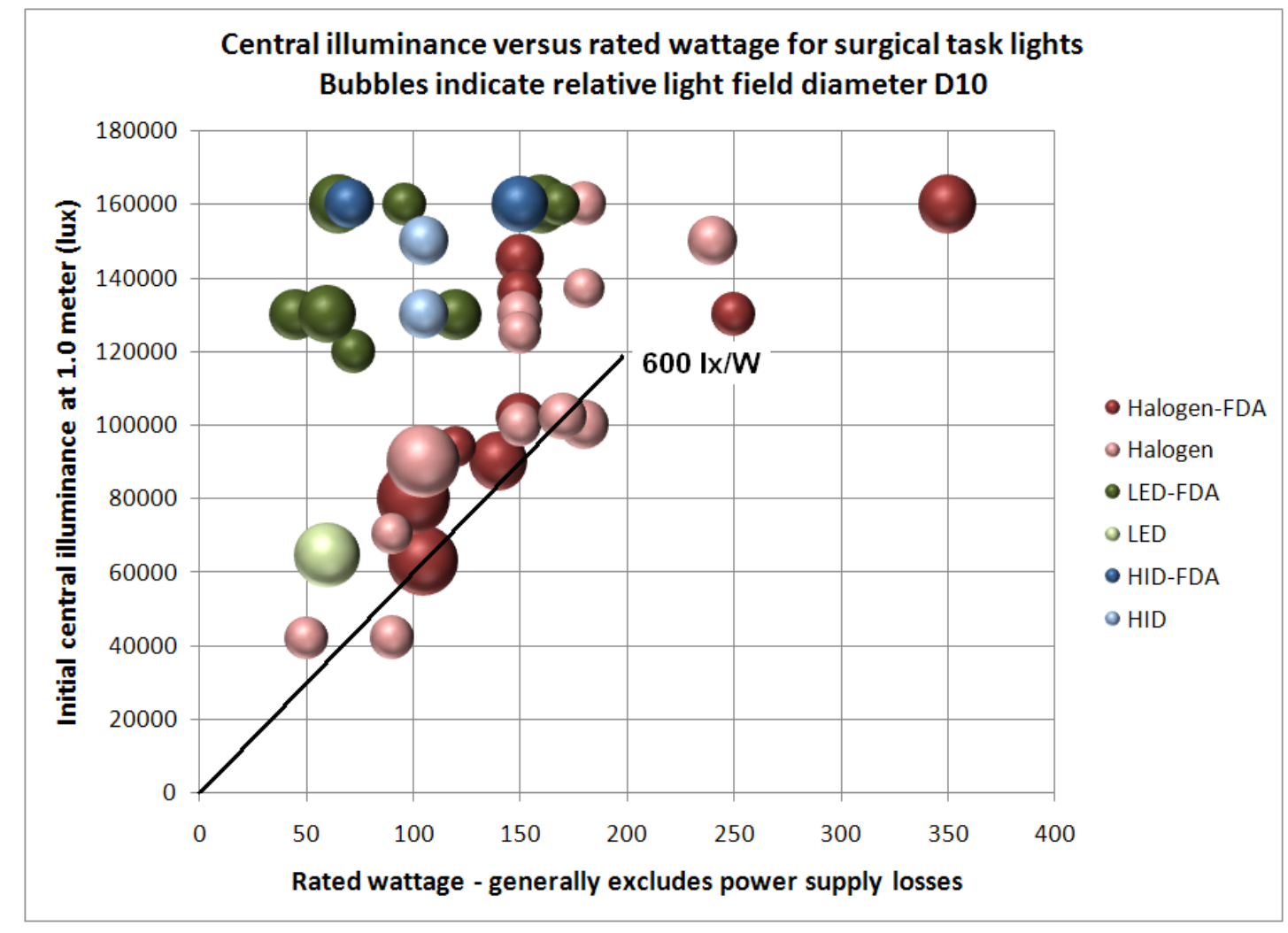

Figure A.2. Survey of performance claims for available products

Lines extending diagonally from the origin/axis of Figure A.2 represent approximately constant efficacy, with diagonals of greater slope indicating greater efficacy and larger bubbles along a given diagonal being more efficacious. LED and high intensity discharge (HID) offer improved efficacy, as expected, but it also appears that these products do not tend to compromise light levels. Among the apparently FDA-approved products, and weighting on the simple basis of field diameter, average initial

\footnotetext{
${ }^{1}$ Qualified products: http://www.accessdata.fda.gov/scripts/cdrh/cfdocs/cfRL/rl.cfm.

${ }^{2}$ Qualified reviewers: http://www.accessdata.fda.gov/scripts/cdrh/cfdocs/cfPCD/classification.cfm?ID=4781.
} 
efficacy (lx/W) ranged from 1848 for LED, to 1630 for HID, and 699 for halogen. For these halogen products, the unweighted average rated input power is approximately $168 \mathrm{~W}$, with a standard deviation of 81. Note that given the prevailing practice of reporting lamp wattage in lieu of luminaire wattage (excluding transformer losses of approximately 16\%), it is assumed that rated LED luminaire wattage excludes power supply losses. Also note that the traditional (architectural) efficacy metric of lumens per watt is not directly applicable here:

- Lacking LM-79 data, we cannot determine total output.

- Even if we only look at "field" lumens, significant error of roughly $26 \%$ (understatement) may be introduced if we simply assume that $\mathrm{d}_{50}$ (which is only rarely reported) occurs halfway to $\mathrm{d}_{10}$.

- Unfortunately, $\mathrm{d}_{50}$ is only reported for two halogen products, so it is not clear whether LED manufacturers are currently exploiting this potential loophole.

- It is therefore best to utilize lux in lieu of lumens for this application. However, efficacy trends and forecasts by DOE are still proportionately applicable (EERE 2010b).

Figure A.3 shows that LED and HID products tend to have comparable color rendering index and slightly higher ("cooler" appearing) correlated color temperature (CCT) than their halogen counterparts. While some LED products are available in a variety of CCTs, efficacy tends to decrease with decreased CCT. Special index R9 (saturated red) is often reported and has logical appeal, but it isn't clear what threshold (if any) is appropriate for this metric.

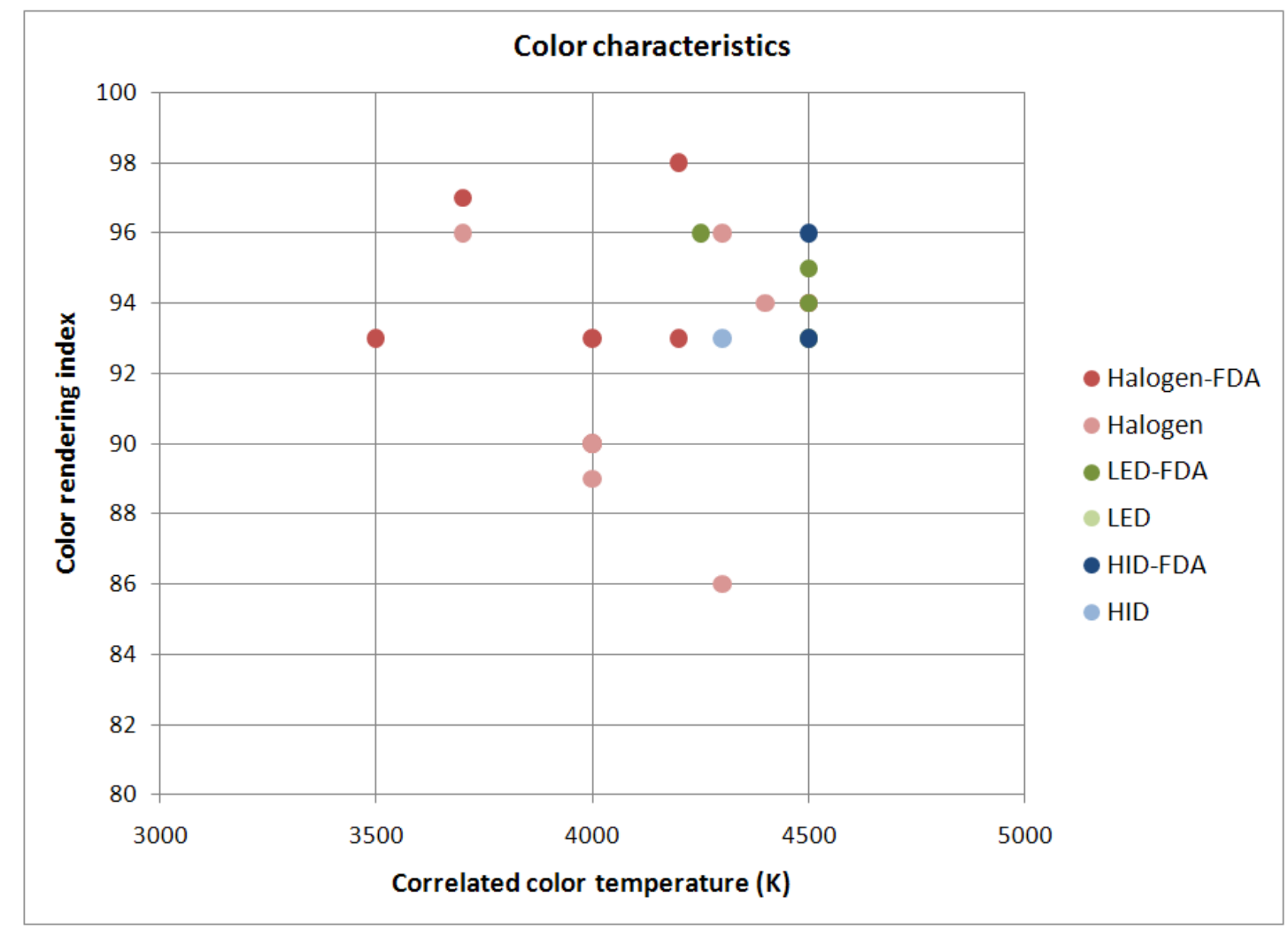

Figure A.3. Colorimetry 
As noted earlier, UV content typically isn't reported in manufacturer literature; the closest statement found was this apparently confused claim by one manufacturer: "Heat emission: Significantly below IEC recommended limit of $10 \mathrm{~W} / \mathrm{m}^{2}$ at highest intensity." Metrics used by manufacturers to indicate nonvisible radiation range from $\mathrm{W} / \mathrm{m}^{2}$ and $\mathrm{mW} / \mathrm{m}^{2} \mathrm{~lx}$ (both per IEC) to $1 \mathrm{~m} / \mathrm{W}$ (where the denominator apparently denotes total visible and non-visible radiation, not input wattage). Non-visible radiation was only reported for one LED product, and at $3.6 \mathrm{~mW} / \mathrm{m}^{2} \mathrm{~lx}$; surprisingly, this offered no advantage over halogen, which averaged just $3.2 \mathrm{~mW} / \mathrm{m}^{2} \mathrm{~lx}$ (with standard deviation of 1.1).

In addition to energy savings, reduced radiation outside the visible spectrum, and equivalent photometric and colorimetric performance, LED technology can offer a much longer useful lifetime. Whereas lifetime for other source types is taken at the 50\% survival point (hours of operation before $50 \%$ of products stop functioning), LEDs are typically rated based on the estimated time elapsed before light output will decrease to $70 \%$ of initial (denoted $\mathrm{L}_{70}$ ). Figure A.4 illustrates the range of rated light source lifetimes within and among the various technologies. Note that it is not clear (seems unlikely) that the FDA has evaluated long-term test data, in situ temperature measurement test data, or manufacturer extrapolation methods to qualify LED useful lifetime claims (EERE 2010c).

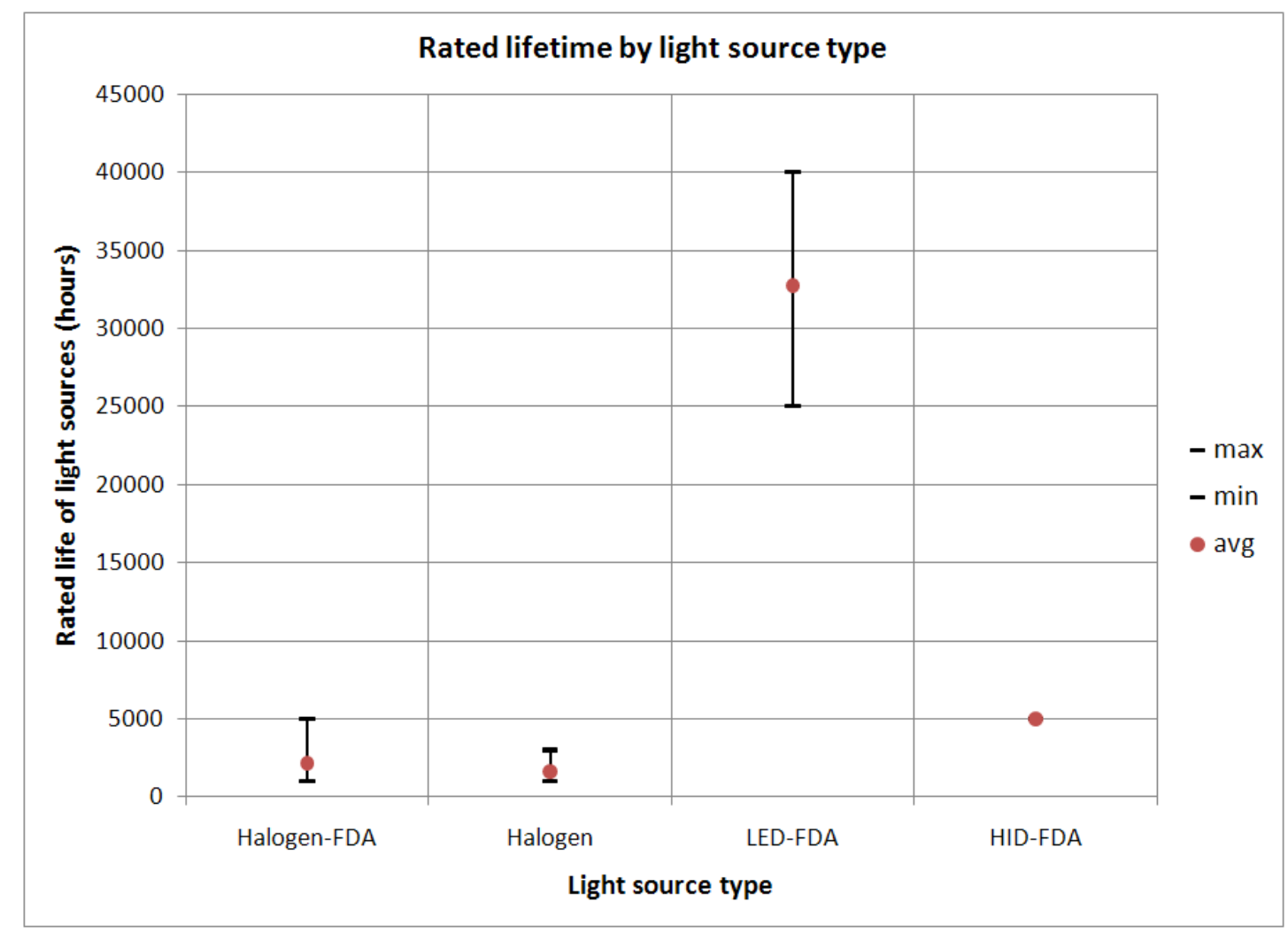

Figure A.4. Rated light source lifetimes

According to Figure 6-20 of the $9^{\text {th }}$ edition IESNA Lighting Handbook (IESNA 2000), halogen lamps produce $95 \%$ of initial output at $70 \%$ of rated life, the IES-recommended time for proactive grouprelamping per RP-36-03. This means that the aforementioned efficacies should be revised accordingly to allow for apples-to-apples comparison of maintained output as follows: 664 lx/W for halogen and 1294 $I x / W$ for LED (lumen maintenance for HID varies and this technology does not appear to be widely 
adopted). This translates to a $49 \%$ reduction in connected load, with some additional savings attributable to reduced cooling load and improved surgical conditions.

Figure A.5 demonstrates the potential for LED products to fall well short of their typical rated lifetimes, and the CALiPER program has revealed countless inaccurate performance claims for initial output from commercial and consumer products (EERE 2010a).

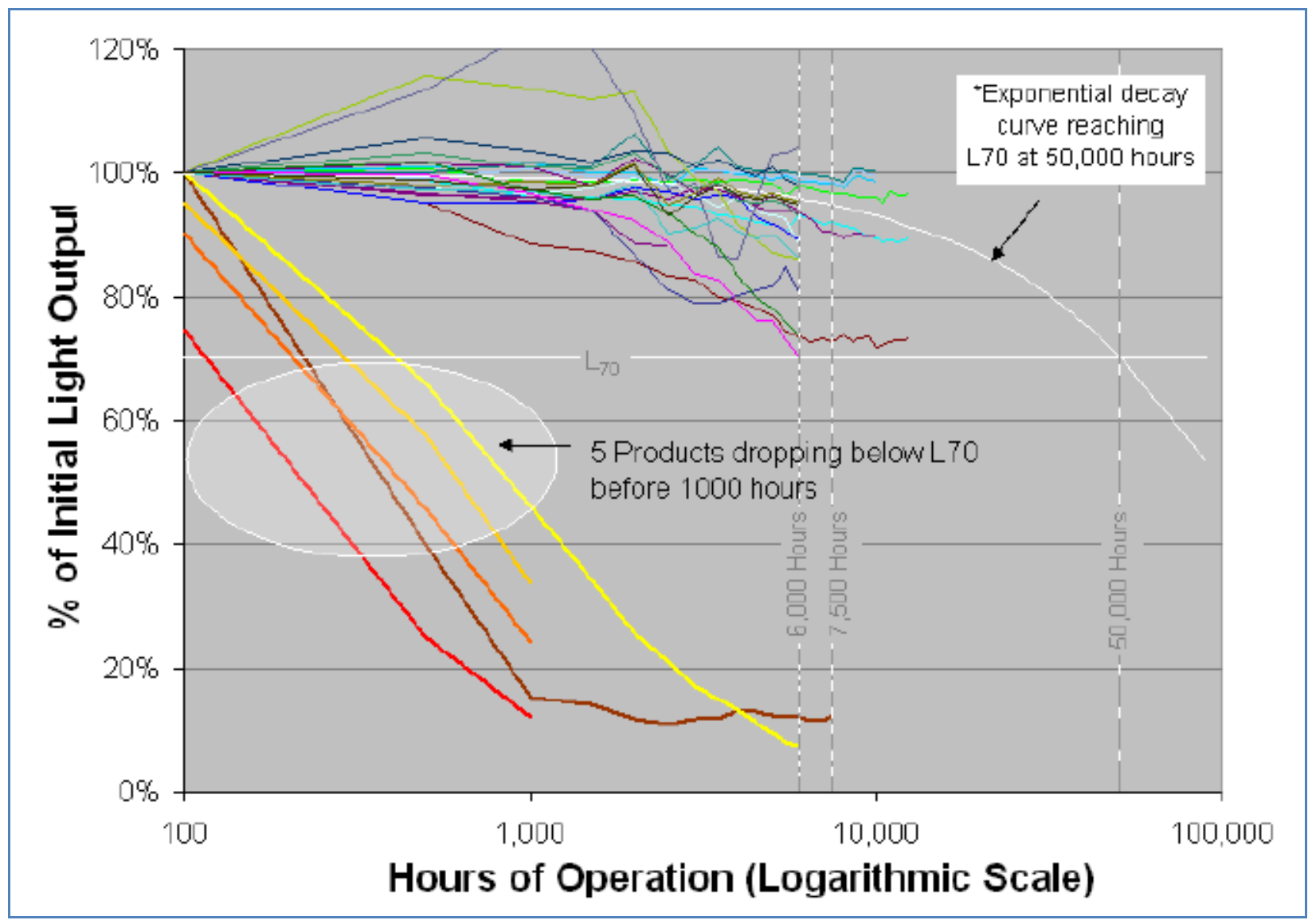

Figure A.5. Long-term testing of LED luminaires and replacement lamps (CALiPER Round 9 Summary)

It is recommended that, in addition to a product specification, and following approval of the forthcoming scoping study, PNNL develop a field-measurement procedure allowing HEA members to verify initial performance and to track maintenance of light output and color of LED surgical task lights. This procedure should be primarily based on the IEC standard to facilitate evaluation of readily available product information, with additions as needed to align with IESNA recommendations and HEA member criteria. 


$$
\text { A. } 7
$$




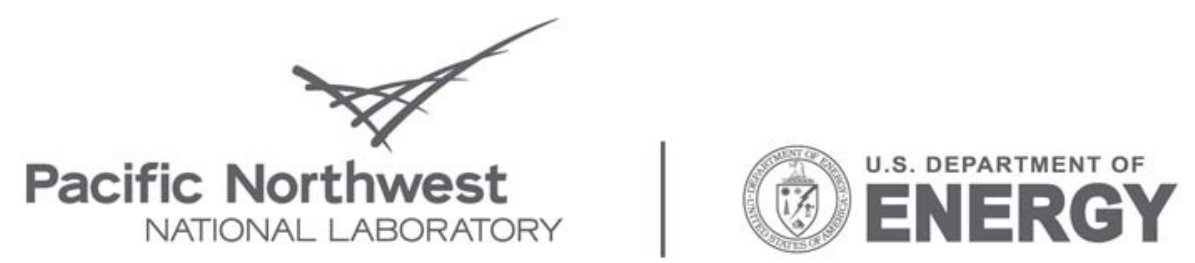

Proudly Operated by Battelle Since 1965

902 Battelle Boulevard

P.O. Box 999

Richland, WA 99352

1-888-375-PNNL (7665)

www.pnl.gov 